\title{
A teleconnection between sea surface temperature in the central and eastern Pacific and wintertime haze variations in southern China
}

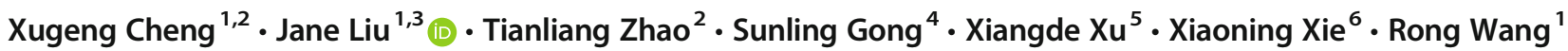

Received: 22 June 2020 / Accepted: 11 October 2020 / Published online: 20 October 2020

(C) The Author(s) 2020

\begin{abstract}
Haze pollution in recent decades varies largely with both pollutant emissions and meteorological conditions. Using the discrete wavelet transform (DWT) method, we separate these two influences on haze variations in southern China in the time series of haze observations from 1981 to 2011. This helps us to identify the meteorological influence on interannual variation in haze occurrences in southern China and thus observe a teleconnection between the thermal forcing of sea surface temperature (SST) in the central and eastern Pacific and wintertime haze occurrences in southern China $(R=-0.51, p<0.05)$. The total haze days in winter is highest among all seasons over southern China and the climotological mean of number of winter haze days is 7.5 days for the region. Compared with the normal winters, the regional mean of the number of haze days in southern China is reduced by $\sim 5$ days in the winters with above-normal Niño3.4 SST (during El Niño phases), but increased by $\sim 4$ days in the winters with below-normal Niño3.4 SST (during La Niña phases). In the warm SST winters, the cumulative consequences of strong winds, more precipitation, and a more unstable atmosphere with an "upper colder and lower warmer" vertical pattern leading to more ascendance can all hinder haze formation, whereas in the cold SST winters, opposite meteorological conditions are favorable to haze formation. These meteorological conditions induced by anomalous SST make wintertime haze pollution in southern China vary from year to year to a large extent. This study suggests a strong sensitivity of winter haze occurrences in southern China to the viability of the SST in the central and eastern Pacific.
\end{abstract}

\section{Introduction}

Haze with high concentrations of aerosols is one of societal and scientific concerns because of its negative effect on human health and ecosystem and its impact on climate change. Southern China (SC), including the Pearl River Delta (PRD), is one of the fastest growing economic areas in China over the last three decades, and thus is among the most polluted areas

Jane Liu

janejj.1iu@utoronto.ca

$\triangle$ Tianliang Zhao

tlzhao@nuist.edu.cn

1 College of Geographic Sciences, Institute of Geography, Key Laboratory of Humid Subtropical Eco-geographical Process (Ministry of Education), Fujian Normal University, Fuzhou 350007, China

2 Collaborative Innovation Center on Forecast and Evaluation of Meteorological Disasters, Key Laboratory for Aerosol-Cloud-Precipitation of China Meteorological Administration, Nanjing University of Information Science and Technology, Nanjing 210044, China in China (Wu et al. 2013b; Zhang et al. 2012). Winter haze events over SC have rapidly increased since 1960s (Ding and Liu 2014; Wu et al. 2013a; Song et al. 2014). Such increases are closely related to the increase of pollutant emissions due to rapid economic development and urbanization (Liu and Diamond 2005; Zhao et al. 2016). Other than pollutant emissions, different meteorological and climatic conditions may exacerbate or alleviate pollution levels (Ding and Liu 2014;

3 Department of Geography and Planning, University of Toronto, Toronto, Canada

4 Institute of Atmospheric Composition, Key Laboratory of Atmospheric Chemistry of China Meteorological Administration (CMA), Chinese Academy of Meteorological Sciences, Beijing 100081, China

5 State Key Laboratory of Severe Weather, Chinese Academy of Meteorological Sciences, Beijing 100081, China

6 State Key Lab of Loess and Quaternary Geology (SKLLQG), Institute of Earth Environment, Chinese Academy of Sciences, Xi'an 710061, China 
Zhang et al. 2014). Meteorological variables, including wind, precipitation, and atmospheric stability, can impact transport, deposition, diffusion, and transition of haze particles (Zhao et al. 2012; Zhang et al. 2014; Sun et al. 2016; Zhao et al. 2016). D. Wu et al. (2005), through analyzing observational data on a severe haze episode over the city of Guangzhou located in SC, reported that the descending air flow and weak horizontal wind could cause more haze pollution. $\mathrm{Wu}$ et al. (2013a) examined the relationship between air quality and the vertical profiles of the atmospheric boundary layer over PRD in two intensive observation campaigns in PRD and found that poor air quality is usually accompanied by calm and low inversion layer. Jacob and Winner (2009) stated that stagnation, mixing depth, and precipitation are the key meteorological factors influencing the level of air pollution.

Previous studies showed that changes in climate systems, atmospheric circulation patterns, and outer-atmospheric forcing factors could modulate aerosol levels and haze frequencies. By simulating aerosol concentrations over 1986-2006 with a global chemical transport model GEOS-Chem, Zhu et al. (2012) reported that the decadal-scale weakening of the East Asian summer monsoon contributed to the increases in summertime aerosol concentrations in eastern China. A few modeling simulations suggested that aerosol concentrations over eastern China were larger in weak East Asian summer monsoon (EASM) years than those in strong EASM years (Zhang et al. 2010; Yan et al. 2011; Cheng et al. 2016). Winter haze in central and eastern China was found to be closely linked to the East Asian winter monsoon (EAWM) on the inter-annual time scale; the weakening of EASM can increase the number of haze days in eastern China ( $\mathrm{Li}$ et al. 2016; Wang and Chen 2016; Yin and Wang 2017). By performing an empirical orthogonal function (EOF) analysis, Zhao et al. (2016) found a positive correlation between the Pacific decadal Oscillation (PDO) index and the second mode of wintertime haze days in eastern China. Xu et al. (2016) emphasized that anomalies in the vertical thermal structure of atmosphere and wind speed associated with the thermal forcing of the Tibetan Plateau changed winter haze days over central and eastern China. The loss of Arctic sea ice was speculated to be related to the increase in the number of haze days in eastern China (Wang et al. 2015; Wang and Chen 2016). The climate forcing factors, such as Atlantic Ocean sea surface temperature (SST) and Eurasian snow cover and Arctic Oscillation (AO), were found to play an important role in the variations of haze occurrences during winter in different regions over China on the interannual time scales (Xiao et al. 2015; Yin and Wang 2018; Lu et al. 2020).

The El Niño-Southern Oscillation (ENSO) is a coupled atmosphere-ocean phenomenon that involves fluctuating ocean temperatures in the equatorial Pacific (Bjerknes 1966; Philandar 1990; Neelin et al. 1998). ENSO is the most dominant forcing factor of interannual climate variability on the planet earth (Lau 1997; Rasmusson and Wallace 1983;
Trenberth and Caron 2000). The warm phase of ENSO, known as El Niño, features warmer than the normal SSTs across the central and eastern equatorial Pacific, while its cold counterpart, La Niña, features an opposite SST anomaly. The ENSO signal is most profound in the central and eastern Pacific. Therefore, SST over this region is widely used to identify ENSO events when interannual climate variability of SST is concerned (Kug et al. 2007).

ENSO has large impacts on meteorological conditions in SC during winter through its significant influence on EAWM. The key system that connects El Niño and EAWM is the Philippine Sea Anticyclone Anomaly (PSAA), resulting from the in situ ocean surface cooling and subsidence, both of which are influenced remotely by warming in the central and eastern Pacific during typical El Niño episodes (Zhang et al. 1996; Wang et al. 2000). Under the influence of this anomalous anticyclone, weak and strong EAWMs usually accompany El Niño and La Niña phases, respectively (Li 1990; Gollan et al. 2012; Wang 2006). In SC, a warmer winter usually corresponds to an El Niño and a colder one to a La Niña (Wang et al. 2000). In the winter of the El Niño mature phase, more rainfall occurs over SC (Zhang et al. 1999; Zhang and Sumi 2002; Zhou and Wu 2010). The dominant interannual variability of wintertime rainfall is also confined to the south of the Yangtze River valley in SC (Wang and Feng 2011).

Earlier studies noticed the impacts of ENSO on haze pollution in China. Because the ENSO phenomenon reaches its highest amplitude and has the strongest impacts on China in winter than in the other seasons (Wang et al. 2000; Wang et al. 2003), the influence of ENSO on haze pollution over China was observed to be the largest in winter (Gao and Li 2015; Chang et al. 2016; Wang et al. 2019; He et al. 2019). It has been reported that the interannual variation of wintertime pollution varies among different regions of China (Jeong et al. 2018; Chang et al. 2016). Meanwhile, the influence of the tropical Pacific SST on the interannual variation appeared most obvious in SC (Li et al. 2017; Zhao et al. 2018; Cheng et al. 2019). In El Niño winters, haze occurrences in SC were found to be lower than the normal, whereas haze in northern China appears to be irrelevant to ENSO (Li et al. 2017; Zhao et al. 2018; He et al. 2019). Yet, Sun et al. (2018) stated that there are large uncertainties in the impact of El Niño on aerosol pollution in SC largely due to the confounding influences from both pollutant emissions and meteorology on haze. Furthermore, the underlying mechanisms and influential meteorological factors for the teleconnection between El Niño and winter haze occurrences in SC have not been systematically explored. Some studies attributed the influences only to a few meteorological factors, such as precipitation. Therefore, we conducted this study to systematically explore a possible teleconnection between ENSO and wintertime haze occurrences in SC, based on observational data from 1981 to 2011. We adopted an approach to differentiate the influences 
of meteorological conditions and pollutant emissions and examined the underlying mechanisms for the teleconnection from multiple meteorological factors that are conducive to haze formation and depletion, including wind field, vertical thermal structure, stability, and precipitation.

The rest of this paper is structured as follows. Section 2 describes data and methods, including a method of signal separation to extract the signal of the meteorological influence on haze pollution in SC. Section 3 explores a teleconnection between the interannual variability of haze occurrences in SC and the SST over the central and eastern Pacific. Section 4 further examines the SST-driven meteorological conditions responsible for the variability of haze pollution. Finally, Section 5 summarizes the main findings from this study.

\section{Data and methodology}

\subsection{Meteorological and emission data}

The following datasets are used in this study: (1) Daily meteorological observations, including visibility, weather phenomenon, relative humidity, precipitation, and 10-m wind from 1981 to 2011 over SC (the mainland China to the east of $107^{\circ} \mathrm{E}$ and south of $29^{\circ} \mathrm{N}$ ) archived by the China Meteorological Administration (CMA). There are 114 stations located in SC area, and totally 85 stations are available over the mainland China (Fig. 1). (2) Monthly data of air temperature, UV wind, and dewpoint are from the reanalysis data from 1980 to 2011 generated by the US National Center for Environmental Prediction-National Center for Atmospheric Research (NCEP/NCAR) (Kalnay et al. 1996). The data are available on $2.5^{\circ}$ latitude $\times 2.5^{\circ}$ longtitude grids and 17 pressure levels from 1000 to $10 \mathrm{hPa}$. (3) Monthly SST data were derived from

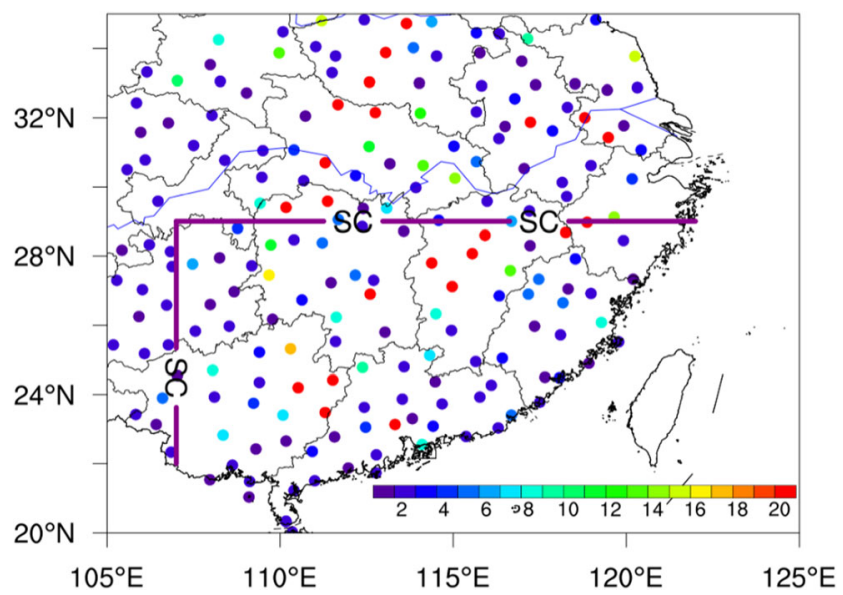

Fig. 1 The climatological mean of the number of winter haze days per winter (unit: days) over the 30-year period in southern China. The study domain is located in the mainland China from the coast line to the east of $107^{\circ} \mathrm{E}$ and south of $29^{\circ} \mathrm{N}$, indicated by two lines, denoted as SC in this study the National Oceanic and Atmospheric Administration (NOAA) extended reconstructed SST version 4 (http://www. cpc.ncep.noaa.gov/data/indices/). (4) The data of carbon monoxide (CO) emissions are based on the global emission inventory from 1980 to 2011 with the horizontal resolution $0.1^{\circ} \times 0$. $1^{\circ}$, which were derived from the Laboratory for Earth Surface Processes, Peking University (http://inventory.pku.edu.cn/) (Zhong et al. 2017). The CO emission averaged over the region $\left(107-125^{\circ} \mathrm{E}\right.$ and $\left.20-29^{\circ} \mathrm{N}\right)$ in used as a proxy for pollutant emissions in SC.

This study adopts a common haze definition that uses surface in-situ observations of visibility, relative humidity, and weather phenomenon (Schichtel et al. 2001; Doyle and Dorling 2002; Ding and Liu 2014). Relative humidity less than $90 \%$ is used to distinguish haze from fog under the visibility $<10 \mathrm{~km}$. A haze day is defined using the average of four daily measurements of RH and visibility, without other weather phenomena such as precipitation and dust storm that may also cause low visibility. Only precipitation events of over $10 \mathrm{~mm}$ within $24 \mathrm{~h}$ are included in the analysis to avoid the effect of hygroscopic growth of aerosols.

Two statistical analyses, correlation and composite, were used. Anomalies for all variables were computed as the deviation from the 30-year climatological mean (1981-2010) in the boreal winter (December, January, and February). The regional mean for a variable is the mean for that variable at 85 stations for station data or the mean for that variable at all grid points within SC for the gridded data. For example, the climotological mean of number of winter haze days in SC 1980 to 2011 is 7.5 days, which is the haze days averaged over SC during that period. To determine extreme SST events in the central and eastern Pacific, the 3-month running mean Niño 3.4 index was used. Niño 3.4 index is defined as the area-averaged anomalous SST within $5^{\circ} \mathrm{S}-5^{\circ} \mathrm{N}$ and $170^{\circ}-120^{\circ} \mathrm{W}$. We selected five above-normal SST winters (1982/1983, 1986/1987, 1991/1992, 1997/1998, 2009/2010) and five below-normal SST winters (1988/1989, 1998/1999, 1999/2000, 2007/2008, 2010/2011) based on a threshold of $\pm 0.9^{\circ} \mathrm{C}$ for Niño3.4 index. These two types of extreme events match the El Niño and La Niña episodes, respectively. In addition, $\mathrm{K}$ index $\left(K_{I}\right)$ is used to characterize the thermodynamic instability of the atmosphere, which is expressed as follows (George 1960):

$K_{I}=\left(T_{850}-T_{500}\right)+T_{d 850}-\left(T_{700}-T_{d 700}\right)$

where $T$ and $T_{d}$ stand for air temperature and dewpoint, respectively, with subscripts 850,700 , and 500 representing 850,700 , and $500 \mathrm{hPa}$, respectively. $K_{I}$ is the major indicator frequently used in weather forecast operations to determine the stability of atmospheric stratification (Haklander and Van Delden 2003; Zhang et al. 2014). $K_{I}$ considers the effect of vertical temperature gradients in lower and middle troposphere $\left(T_{850}-T_{500}\right)$, the water vapor condition at $850 \mathrm{hPa}\left(T_{d 850}\right)$ and the saturation 
conditions at $700 \mathrm{hPa}\left(T_{700}-T_{d 700}\right)$. Therefore, the larger the $K_{I}$ is, the more unstable the atmospheric stratification is.

\subsection{Separation of low-frequency and high-frequency components}

The wavelet analysis is a powerful tool for extracting information in different variation frequencies from a time series. A time series $Y(t)$ of an observed species can be expressed as two different unobservable parts, a trend $T(t)$ and a stochastic component $X(t)$ :

$Y(t)=T(t)+X(t)$.

Wavelet analysis is a transformation that divides $Y(t)$ into two types of coefficients: the scaling coefficients and the wavelet coefficients. The summation of the two types of coefficients is totally equivalent to $Y(t)$ because wavelet analysis should be able to reconstruct the original time series. The scaling coefficients are related to the averages at a specified scale, while wavelet coefficients can be associated with the changes of the averages over specific scales. Since the scale in the scaling coefficients is usually fairly large, the information that these coefficients capture corresponds to the notion of the trend (Daubechies 1990). Wavelet analysis allows the use of long-time periods for low- frequency (LF) information, and short-term periods for highfrequency (HF) information. High scales represent the stretched version of a wavelet and their corresponding coefficients, indicating slowly changing features of a LF component (Küçük and Ağiralioğlu 2006), while low scales are the compressed wavelet, following a HF component. The main advantage of the wavelet method is its robustness, as it does not require any potentially erroneous assumptions or parametric testing procedures (Kişi 2009). Another advantage is that wavelet variance decomposition allows one to study different changes in different time scales independently (Adarsh and Janga Reddy 2015). The mathematical derivations for the scaling and wavelet coefficients are well documented in literature (Daubechies 1990, 1992; Kumar and Foufoula-Georgiou 1997; Capilla 2008).

Haze occurrences depend largely on pollutant emissions and meteorological conditions. As the dataset of haze days is discrete, it is appropriate to analyze the time series of haze days using the discrete wavelet transform (DWT) method, making it possible to separate the influence of meteorology from that from pollutant emissions. In this study, the time series of winter haze observations and its decomposed components are based on a three-level Daubechies 6 wavelet with a LF component (i.e., the trend) and three HF components (i.e., the interannual variability) via the DWT approach. The sum of the three HF components and the LF component is
Fig. 2 a Time series of wintertime $\mathrm{CO}$ emission levels (in $\mathrm{kg} \mathrm{km}^{-3}$ ) averaged over SC, the total number of winter haze days and its wavelet-decomposed LF component, the sum of three HF components in SC (all in day), and the SST anomalies (in ${ }^{\circ}$ ) in winter from 1981 to 2011. b Map of the correlation coefficients between Niño 3.4 index and the sum of three HF components averaged over SC during winters from 1981 to 2010 (shadings). The rectangle represents the Niño 3.4 region $\left(5^{\circ} \mathrm{S}-5^{\circ} \mathrm{N}\right.$ and $170^{\circ}-$ $\left.120^{\circ} \mathrm{W}\right)$. The contour lines of 0.35 $(-0.35)$ and $0.45(-0.45)$ indicate values at $95 \%$ and $99 \%$ confidence levels, respectively
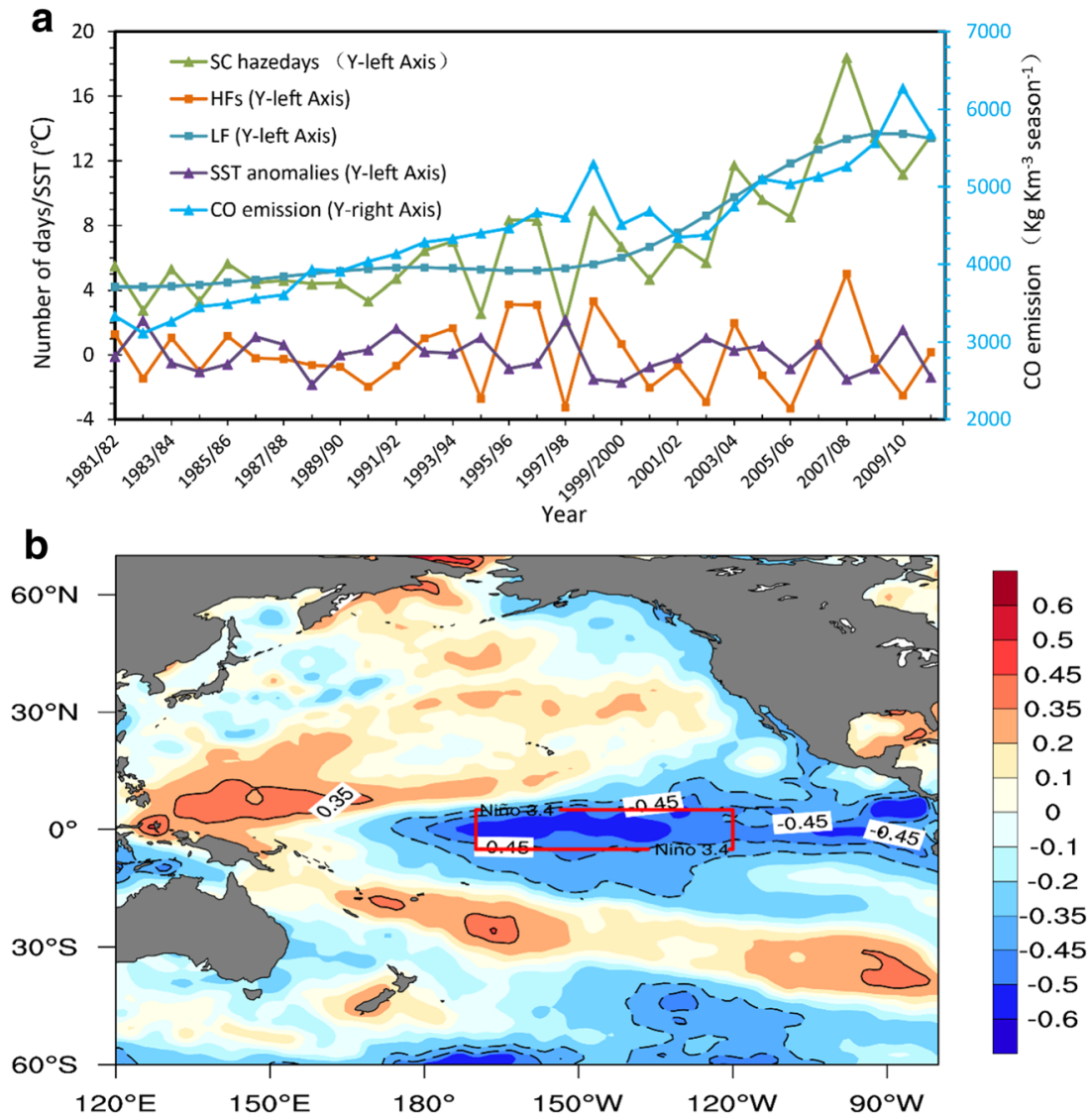
equal to the original time series. Figure 2 a shows the time series of winter haze days over SC and its HF and LF components decomposed using DWT. The HF components have higher frequencies, which represent the rapidly changing component of the time series, whereas the LH component represents the slowly changing component. The general idea behind identifying the influence of meteorology from that from emissions with wavelets is to associate the LF component with the emission and the HF components with the meteorology. The corresponding explanation will be shown in Section 3.

\section{Interannual variability of wintertime haze occurrences in southern China and its sensitivity to Niño 3.4 SST}

Being a proxy for pollutants from fossil fuel combustion, $\mathrm{CO}$ emissions is an indicator frequently used to explain variations in pollutant emissions over certain regions. Figure 2a shows an increasing trend in pollutant emissions over the past three decades in SC, which appears to be connected to rapid increase of observed wintertime haze occurrences in SC during the same period. The correlation coefficient between $\mathrm{CO}$ emissions and haze occurrences is 0.71 (Table 1), implying that regional emissions of air pollutants is one of the main contributors to the decadal increase in haze pollution in SC. However, regarding the interannual variations, haze occurrences and meteorology coincide to some extent, suggesting an important role that meteorology plays in modulating this variation.

It is necessary to remove the contribution of pollutant emissions from haze observations when analyzing the relationship between SST and haze pollution. By performing DWT analysis, the trend and interannual variability of winter haze occurrences are identified. The LF component, which describes the trend, correlates well with the $\mathrm{CO}$ emissions from 1981 to $2010(R=$ $0.84)$, better than the correlation between the original haze occurrences and $\mathrm{CO}$ emissions (Table 1). Thus, it is most likely that

Table 1 Correlation coefficients between relevant factors or variables in winters from 1981 to $2011^{1}$

\begin{tabular}{llll}
\hline & Haze occurrences & $\begin{array}{l}\text { Haze LF } \\
\text { component }\end{array}$ & $\begin{array}{l}\text { Haze HF } \\
\text { components }\end{array}$ \\
\hline CO & $0.71^{* *}$ & $0.84^{* *}$ & - \\
Detrended CO & - & - & 0.16 \\
Niño3.4 SST & $-0.39^{*}$ & - & $-0.51^{* *}$ \\
\hline
\end{tabular}

${ }^{1}$ Except the Niño3.4 SST, the other variables are averaged over SC. LF component and HF components represent the wavelet-decomposed LF component, the sum of three HF components by performing the DWT to the original haze time series (see Fig. 2a). Values marked with one asterisk and two asterisks indicate significance at the $95 \%$ and $99 \%$ confidence levels, respectively the observed decadal increasing trend of haze occurrences is primarily due to the increasing pollutant emissions in SC. Meanwhile, considerable interannual variability is shown in the three HF components that represent short-term variations (Fig. 2a). The separation of LH and HF components enables us to observe a close connection between the sum of three HF components and meteorology. The correlation between the sum of the three HF components and Niño 3.4 index is -0.51 , passing the $99 \%$ confidential level (Table 1). Furthermore, we linearly detrended the original $\mathrm{CO}$ time series, and the detrended time series of $\mathrm{CO}$ show no apparent connection with the sum of the three HF components $(R=0.16$; Table 1$)$. Based on above analyses, it is likely that Niño3.4 SST is teleconnected with the winter haze occurrences in SC.

Figure $2 \mathrm{~b}$ shows additional evidence for the teleconnection between the tropical Pacific SST and the interannual variation in wintertime haze over SC. Negative correlations of $\sim-0.50$ are observed in the central and eastern Pacific (Niño 3.4 region), while positive correlations of $\sim-0.35$ appear in the
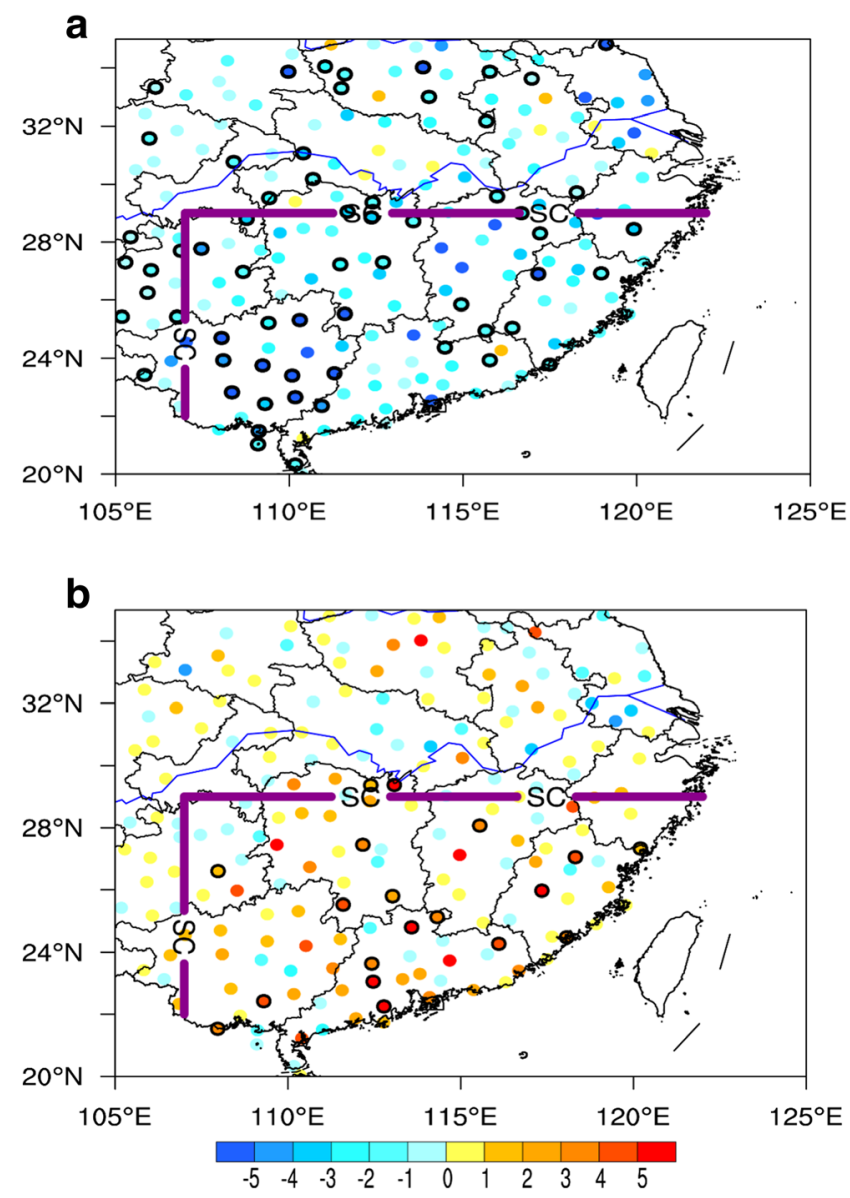

Fig. 3 Anomalies of the sum of three HF wavelet components of winter haze day per winter (in days) a mean of the five above-normal SST winters (1982/1983, 1986/1987, 1991/1992, 1997/1998, 2009/2010) and $\mathbf{b}$ mean of the five below-normal SST winters (1988/1989, 1998/1999, 1999/2000, 2007/2008, 2010/2011). The composite passing the $95 \%$ confidence level is marked with a black circle around a dot 
western Pacific (warm pool). This spatial variation reflects the typical west-east seesaw pattern of interannual variability of tropical Pacific SST (Rasmusson and Wallace 1983; Neelin et al. 1998). This dipole pattern verifies that the Niño3.4 SST over the entire tropical Pacific region is an effective indicator to the interannual variations of winter haze occurrences in SC. Positive (negative) Niño3.4 SST anomalies are likely associated with more (less) haze occurrences in SC in winter.

The anomalies in winter haze occurrences in SC exhibit the opposite patterns in two extreme phases of Niño 3.4 SST (Fig. 3 ). The composite of anomalies of winter haze occurrences in the HF components were compared between five above-normal SST winters (Fig. 3a) and five below-normal SST winters (Fig. $3 b)$. In winters with above-normal SST, the regional mean of haze occurrences is lower than the normal by 5 days per winter. In contrast, in winters with below-normal SST, the regional mean haze occurrences are up to 4 days more than the normal.

\section{Mechanisms of a teleconnection between Niño 3.4 SST and interannual variability of wintertime haze occurrences in southern China}

The meteorological conditions favorable to haze occurrences include low wind speed, stable low-level stratification, and less precipitation. Therefore, how Niño3.4 SST could alter these meteorological conditions in winter over SC is examined as follows.

\subsection{Winds}

Figure $4 \mathrm{a}$ and $\mathrm{b}$ shows the composite anomalies in wind speed and wind field at $850 \mathrm{hPa}$ during five above-normal SST winters and five below-normal SST winters, respectively. In the winters with above-normal SST winters, strong southerlies prevail, and anomalous positive wind speed is apparent in SC (Fig. 4a). In contrast, in winters with the below-normal SST, meridional winds prevail over SC and form a region of weaker wind (Fig. 4b). To verify that the anomalies in wind field in different SST phase induced by thermal forcing of Niño3.4 SST, two components of the correlation vector are derived: the correlation in the $x$ direction between $\mathrm{U}$ at $850 \mathrm{hPa}$ and Niño3.4 SST anomalies and the correlation in the $y$ direction between $\mathrm{V}$ at $850 \mathrm{hPa}$ and Niño3.4 SST anomalies. The arrow length denotes the combined correlation with a longer arrow implying a better correlation, and the arrow direction means the direction of anomalous wind potentially induced by SST anomalies. In winters with above-normal SST, a divergence pattern of the correlation vectors forms over the western Pacific with a center over the Philippine Sea (Fig. 4c), which is exactly the PSAA during the winters
Fig. 4 a and $\mathbf{b}$ The anomalies of wind speed (in $\mathrm{m} \mathrm{s}^{-1}$ ) (shadings) at $850 \mathrm{hPa}$. The mean of the five above-normal SST winters (1982/1983, 1986/1987, 1991/1992, 1997/1998, 2009/2010) (a) and the mean of the five below-normal SST winters $(1988 / 1989,1998 / 1999$, 1999/2000, 2007/2008,

2010/2011) (b). Correlations of the Niño3.4 index to the Vcomponent of $850-\mathrm{hPa}$ wind in winters over 1981-2011. Arrows denote the correlation vector derived through two correlation coefficients of Niño3.4 SST anomalies to U- and $\mathrm{V}-850 \mathrm{hPa}$ wind components, respectively (c). The levels of $0.35(-0.35)$ and $0.45(-0.45)$ indicate values at the $95 \%$ and $99 \%$ confidence levels, respectively a

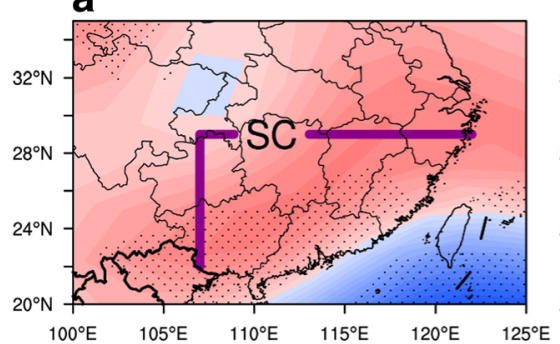

b

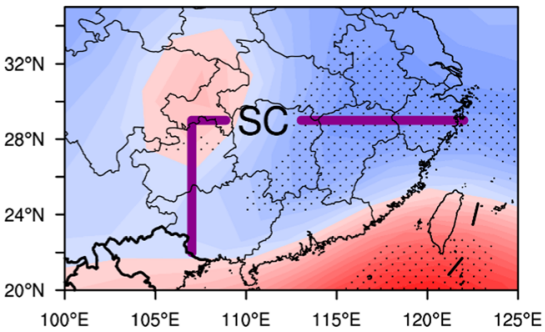

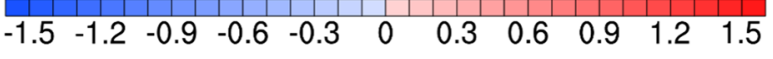

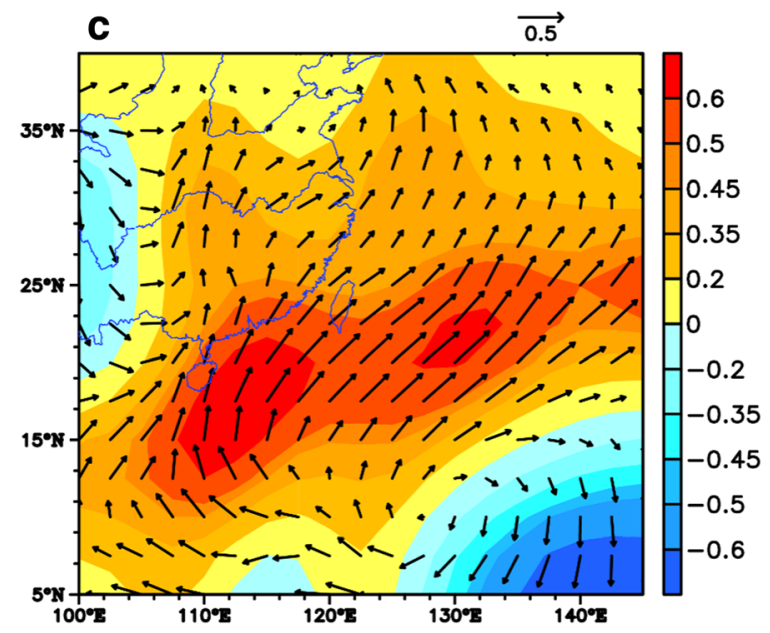


Fig. 5 Vertical cross sections of air temperature anomalies $\left({ }^{\circ} \mathrm{C}\right)$ (shadings) and vertical pressure velocity anomalies $\left(10^{-2} \mathrm{~Pa} \mathrm{~s}^{-1}\right)$ (contours) averaged between 20 and $30^{\circ} \mathrm{N}$ a over the five abovenormal SST winters $(1982 / 1983$, 1986/1987, 1991/1992, 1997/1998, 2009/2010) and b over the five below-normal SST winters $(1988 / 1989,1998 / 1999$, 1999/2000, 2007/2008,

2010/2011). c Time series of $K_{I}$ averaged over SC and Niño3.4 SST from 1980 to 2010. The vertical red and blue lines illustrate the typical winters with above-normal and below-normal SST, respectively
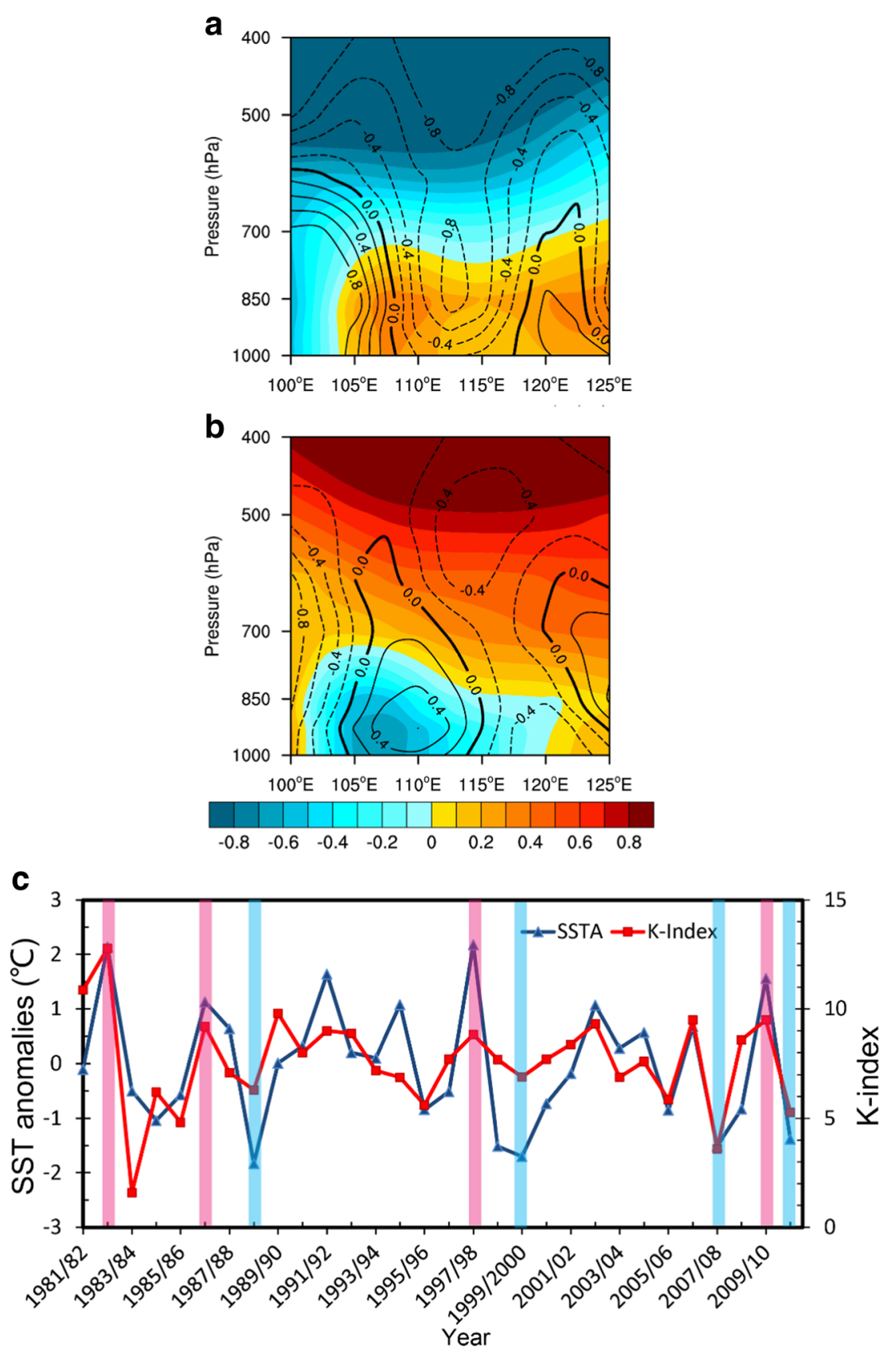

with positive Niño3.4 index. This PSAA results from a Rossby-wave response to suppressed convective heating, which is induced by the subsidence forced remotely by warming in Niño3.4 SST (Wang et al. 2000). Anomalous southerlies prevail SC, which is located northwest of the PSAA. Therefore, the associated anomalous southerlies superimpose on the mean wind at $850 \mathrm{hPa}$ (weak southerlies, not shown). This tends to intensify wind speed and transport clean air to SC. This condition is not conductive to accumulation of air pollutants. In contrast, in the below-normal SST winters, the wind anomalies are largely opposite to these in warm SST winters, and thus, wind speed over SC is reduced and formation of haze is enhanced.

\subsection{Thermal structures and stabilities}

To show the thermal structures in winter over SC, we made composite analysis on vertical air temperature in winters, with five most positive and five most negative SST anomalies in the Niño3.4 region. The air temperature changes with upper cooler and lower warmer pattern are found in the middle and lower troposphere in winters with the above-normal SST (Fig. 5a). This warmer condition in lower levels is associated with the anomalous southerlies bringing warm air to SC (Fig. 3c), which weakens the cold surge from northern China (Wang et al. 2000). The vertical structure of temperature anomalies bears a reverse thermal 
structure in winters with negative Niño3.4 SST anomalies (Fig. 5b). These two abnormal structures with opposite changes in the middle and lower troposphere have been found in Xu et al. (2016), who name the vertical structure patterns "cold shield" (Fig. 5a) and "warm shield" (Fig. $5 b)$, respectively. The vertical variations of air temperature with a "cool shield" pattern could easily build an inversion layer accompanied with the anomalous ascendance in the lower troposphere, which result in a more stably stratified atmosphere in this region and is responsible for the regional frequent haze occurrences. To test the atmospheric stabilities in these two vertical structures of air temperature, we introduced an index $K_{I}$ to represent the stratification stability of moist air in lower and middle troposphere. The larger the $K_{I}$, the more unstable the atmosphere. The $K_{I}$ averaged over SC is higher than the normal in winters with the above-normal SST but lower than the normal in the winters with below-normal SST (Fig. 5c). The correlation between the $K_{I}$ and the Niño3.4 SST is also significantly positive, suggesting that the stability in the lower and middle troposphere in SC is reduced (enhanced) in the winters with warm (cold) Niño3.4 SST. The existence of the atmospheric inversion layer processes in winter has found to be highly related with heavy haze pollution (Xu et al. 2003; Zhang et al. 2014). It is shown here that in the winters with below-normal SST, the associated stable atmosphere tends to build an inversion layer over SC, and thus to enhance haze occurrences, whereas in winters with below-normal SST, an unstable atmosphere stratification tends to reduce haze occurrences.
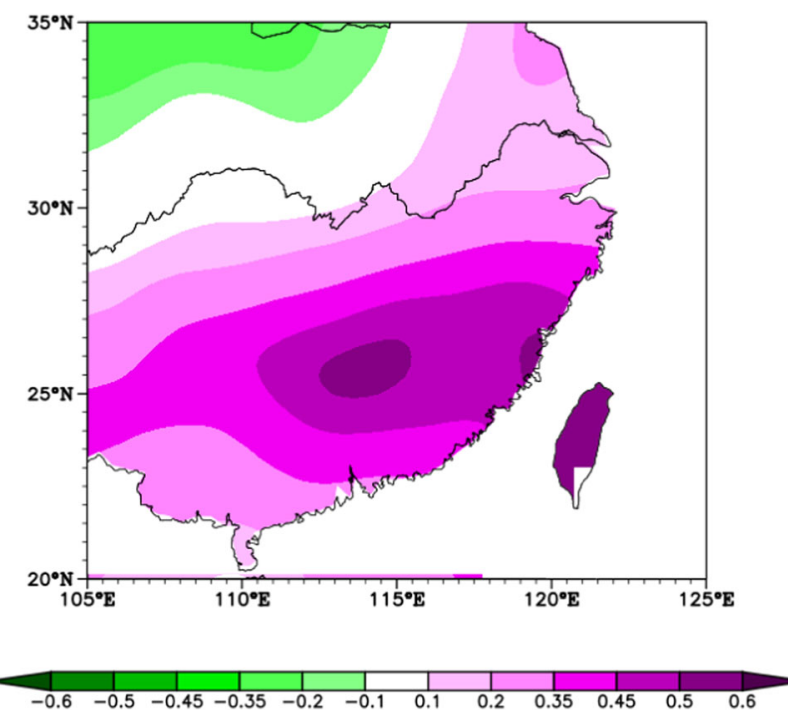

Fig. 6 Map of correlation coefficients between the Niño3.4 index and precipitation in winters from 1981 to 2011 . Precipitation events at a station with less than $10 \mathrm{~mm}$ within $24 \mathrm{hr}$ have been excluded from the analysis (see text). The levels of $0.35(-0.35)$ and $0.45(-0.45)$ indicate values at the $95 \%$ and $99 \%$ confidence levels, respectively

\subsection{Precipitation}

Wet deposition due to precipitation is a major aerosol removal process in the atmosphere. In winters with the above-normal Niño3.4 SST, more precipitation occurs in SC, because of strong anomalous southerlies from the PSAA carrying moisture into the mainland China (Zhang et al. 1996, 1999). Excluding cases with precipitation below $10 \mathrm{~mm}$ within $24 \mathrm{~h}$, Niño3.4 SST is correlated with precipitation in SC in winter (Fig. 6). The correlation coefficient is above 0.35 in most SC, suggesting that the washout effect of air pollutants in SC could be strengthened (weaken) when Niño3.4 SST is the above-normal (above-below).

\section{Conclusions}

Based on analysis of wintertime observations from 1981 to 2011, we show that a teleconnection between the Niño3.4 SST and haze occurrences in SC. Through the DWT analysis, the time series of wintertime haze days over SC is decomposed into a LF component and three HF components, which represent the long-term trend and the short-term variability in the observational time series, respectively. In longterm, $\mathrm{CO}$ emissions over $\mathrm{SC}$, a proxy for pollutant emissions, are positively correlated with the LF component $(R=0.95)$. Thus, the decadal increasing trend of haze days in the observational data is likely associated with the increasing emissions in SC during this period. In short-term, the interannual variation in the sum of the three HF components is negatively correlated with simultaneous Niño3.4 SST anomalies $(R=-$ 0.51 ). The number of haze days in SC is fewer/more in winters with above-normal/below-normal Niño3.4 SST than in the normal winters. The anomalies in wind speed, vertical air temperature, atmospheric stratification, and precipitation induced by the thermal forcing of Niño3.4 SST can well explain the differences in haze days over SC between winters with above-normal/below-normal Niño3.4 SST. In winters with the above-normal SST, the cumulative consequences of stronger winds, more unstable atmosphere and more wet deposition are all unfavorable to haze formation over SC. In contrast, the opposite meteorological conditions are apparent in winters with below-normal SST. Therefore, the interannual variation of winter haze occurrences in SC is closely teleconnected to the variation in the Niño3.4 SST.

Results from this study have important implications for forecasting air quality in SC. There are several prediction schemes that are constructed for seasonal chemistry weather forecasts based on SST (Colman and Davey 2003; Sohn et al. 2016), due to the important role of SST in inciting lowfrequency atmospheric changes (Lau 1997; Shukla et al. 2000). It has been found that ENSO can be predicted better during SST extreme events than in the normal periods (Jin et al. 2008). Accordingly, SST is one of the key factors to 
consider when seasonal to inter-annual climate variations are concerned (Kug et al. 2007). Therefore, the correlation of haze pollution to SST anomalies found in this study may bring a new prospective for the seasonal forecast of haze pollution in SC. Moreover, air quality models can be used to quantitatively evaluate the impact of the tropical Pacific SST on haze variations in China in the future. The impacts of SST on air quality can be further studied from perspectives of shifts in weather patterns, pollutant emissions, depositions, and chemical reactions in the atmosphere.

It is noteworthy that El Niño events can be divided into the eastern Pacific (EP) El Niño and the central Pacific (CP) El Niño, each of which impacts atmospheric circulation and aerosol concentrations in East Asia differently. The extremely warm SST events in this study correspond to the EP El Niño. While the influences of the CP El Niño on the atmospheric particles in East Asia (Jeong et al. 2018) and in China (Yu et al. 2019) were documented, how CP El Niño impacts haze in SC requires further exploration. This study found a teleconnection of the SST in the tropical Pacific to winter haze pollution in SC. However, no similar teleconnection to winter haze pollution was found in northern China. Other climate factors, such as the Arctic sea ice (Wang and Chen 2016; Yin and Wang 2017) and Arctic Oscillation (Lu et al. 2020), may play a role in modulating haze pollution in northern China. Further studies can also be carried out to separate the individual influences of different climatic modes on haze pollution in China and around the world.

Acknowledgments The carbon monoxide data provided by the Laboratory for Earth Surface Processes of Peking University and the SST and meteorological data provided by NOAA and NCEP/NCAR are acknowledged. We gratefully thank the two anonymous reviewers for their constructive and valuable suggestions and comments.

Credit authorship contribution statement Xugeng Cheng: conceptualization, writing - original draft. Jane Liu: supervision, Writing - review and editing. Tianliang Zhao: funding acquisition, supervision, methodology. Sunling Gong: methodology, software. Xiangde Xu and Xiaoning Xie: data analysis, revision. Rong Wang: data analysis, revision, English editing. All the authors discussed the results.

Funding This work was supported by the National Natural Science Foundation of China (No. 41830965, 91744209) and the National Key R \& D Program Pilot Projects of China (CN) (2016YFC0203304).

Open Access This article is licensed under a Creative Commons Attribution 4.0 International License, which permits use, sharing, adaptation, distribution and reproduction in any medium or format, as long as you give appropriate credit to the original author(s) and the source, provide a link to the Creative Commons licence, and indicate if changes were made. The images or other third party material in this article are included in the article's Creative Commons licence, unless indicated otherwise in a credit line to the material. If material is not included in the article's Creative Commons licence and your intended use is not permitted by statutory regulation or exceeds the permitted use, you will need to obtain permission directly from the copyright holder. To view a copy of this licence, visit http://creativecommons.org/licenses/by/4.0/.

\section{References}

Adarsh S, Janga Reddy M (2015) Trend analysis of rainfall in four meteorological subdivisions of southern India using nonparametric methods and discrete wavelet transforms. Int J Climatol 35(6):1107-1124

Bjerknes J (1966) A possible response of the atmospheric Hadley circulation to equatorial anomalies of ocean temperature. Tellus 18(4): $820-829$

Capilla C (2008) Time series analysis and identification of trends in a Mediterranean urban area. Glob Planet Chang 63(2-3):275-281

Chang L, Xu J, Tie X, Wu J (2016) Impact of the 2015 El Niño event on winter air quality in China. Sci Rep 6(1):1-6

Cheng X, Zhao T, Gong S, Xu X, Han Y, Yin Y, Tang L, He H, He J (2016) Implications of East Asian summer and winter monsoons for interannual aerosol variations over central-eastern China. Atmos Environ 129:218-228

Cheng X, Boiyo R, Zhao T, Xu X, Gong S, Xie X, Shang K (2019) Climate modulation of Niño3. 4 SST-anomalies on air quality change in southern China: Application to seasonal forecast of haze pollution. Atmos Res 225:157-164

Colman AW, Davey MK (2003) Statistical prediction of global seasurface temperature anomalies. Int J Climatol 23(14):1677-1697

Daubechies I (1990) The wavelet transform, time-frequency localization and signal analysis. IEEE Trans Inf Theory 36(5):961-1005

Daubechies I (1992) Ten Lectures on Wavelets. Cambridge Univ. Press, Cambridge

Ding Y, Liu Y (2014) Analysis of long-term variations of fog and haze in China in recent 50 years and their relations with atmospheric humidity. Sci China Earth Sci 57(1):36-46

Doyle M, Dorling S (2002) Visibility trends in the UK 1950-1997. Atmos Environ 36(19):3161-3172

Gao H, Li X (2015) Influences of El Niño Southern Oscillation events on haze frequency in eastern China during boreal winters. Int J Climatol 35(9):2682-2688

George JJ (1960) Weather Forecasting for Aeronautics. Academic Press, New York, p 673

Gollan G, Greatbatch RJ, Jung T (2012) Tropical impact on the East Asian winter monsoon. Geophys Res Lett 39(17)

Haklander AJ, Van Delden A (2003) Thunderstorm predictors and their forecast skill for the Netherlands. Atmos Res 67:273-299

He C, Liu R, Wang X, Liu SC, Zhou T, Liao W (2019) How does El Niño-Southern Oscillation modulate the interannual variability of winter haze days over eastern China? Sci Total Environ 651: 1892-1902

Jacob DJ, Winner DA (2009) Effect of climate change on air quality. Atmos Environ 43(1):51-63

Jeong JI, Park RJ, Yeh SW (2018) Dissimilar effects of two El Niño types on PM2. 5 concentrations in East Asia. Environ Pollut 242:1395-1403

Jin EK, Kinter JL III, Wang B, Park CK, Kang IS, Kirtman BP, Kug JS, Kumar A, Luo JJ, Schemm J, Shukla J, Yamagata T (2008) Current status of ENSO prediction skill in coupled ocean-atmosphere models. Clim Dyn 31(6):647-664

Kalnay E, Kanamitsu M, Kistler R, Collins W, Deaven D, Gandin L, Iredell M, Saha S, White G, Woollen J, Zhu Y, Leetmaa A, Revnolds R, Chelliah M, Ebisuzaki W, Higgins J, Janowiak J, Mo CK, Ropelewski C, Wang J, Jenne R, Joseph D (1996) The NCEP/NCAR 40-year reanalysis project. Bull Am Meteorol Soc 77(3):437-472

Kiși Ö (2009) Wavelet regression model as an alternative to neural networks for monthly streamflow forecasting. Hydrol Process 23(25): 3583-3597

Küçük M, Ağiralioğlu N (2006) Wavelet regression technique for streamflow prediction. J Appl Stat 33(9):943-960 
Kug JS, Lee JY, Kang IS (2007) Global sea surface temperature prediction using a multimodel ensemble. Mon Weather Rev 135(9):3239-3247

Kumar P, Foufoula-Georgiou E (1997) Wavelet analysis for geophysical applications. Rev Geophys 35(4):385-412

Lau NC (1997) Interactions between global SST anomalies and the midlatitude atmospheric circulation. Bull Am Meteorol Soc 78(1):21-34

Li C (1990) Interaction between anomalous winter monsoon in East Asia and El Niño events. Adv Atmos Sci 7(1):36-46

Li Q, Zhang R, Wang Y (2016) Interannual variation of the wintertime fog-haze days across central and eastern China and its relation with East Asian winter monsoon. Int J Climatol 36(1):346-354

Li S, Han Z, Chen H (2017) A comparison of the effects of interannual Arctic sea ice loss and ENSO on winter haze days: observational analyses and AGCM simulations. J Meteor Res 31(5):820-833

Liu J, Diamond J (2005) China's environment in a globalizing world. Nature 435(7046):1179-1186

Lu S, He J, Gong S, Zhang L (2020) Influence of Arctic Oscillation abnormalities on spatio-temporal haze distributions in China. Atmos Environ 223:117282

Neelin JD, Battisti DS, Hirst AC, Jin FF, Wakata Y, Yamagata T, Zebiak SE (1998) ENSO theory. J Geophys Res Oceans 103(C7):14261-14290

Philandar SG (1990) El Niño, La Niña, and the Southern Oscillation, vol 289. Academic Press, London

Rasmusson EM, Wallace JM (1983) Meteorological aspects of the El Niño/Southern Oscillation. Science 222(4629):1195-1202

Schichtel BA, Husar RB, Falke SR, Wilson WE (2001) Haze trends over the United States, 1980-1995. Atmos Environ 35(30):5205-5210

Shukla J, Anderson J, Baumhefner D, Brankovic C, Chang Y, Kalnay E, Marx L, Palmer T, Paolino D, Ploshay J, Schubert S, Straus D, Suarez M, Tribbia J (2000) Dynamical seasonal prediction. Bull Am Meteorol Soc 81(11):2593-2606

Sohn SJ, Tam CY, Jeong HI (2016) How do the strength and type of ENSO affect SST predictability in coupled models? Sci Rep 6(1):1-8

Song LC, Gao R, Ying LI, Wang GF (2014) Analysis of China's haze days in the winter half-year and the climatic background during 1961-2012. Adv Clim Chang Res 5(1):1-6

Sun Y, Chen C, Zhang Y, Xu W, Zhou L, Cheng X, Zheng H, Ji D, Li J, Tang X, Fu P, Wang Z (2016) Rapid formation and evolution of an extreme haze episode in Northern China during winter 2015. Sci Rep 6(1):1-9

Sun J, Li H, Zhang W, Li T, Zhao W, Zuo Z, Guo S, Wu D, Fan S (2018) Modulation of the ENSO on winter aerosol pollution in the eastern region of China. J Geophys Res Atmos 123(21):11-952

Trenberth KE, Caron JM (2000) The Southern Oscillation revisited: sea level pressures, surface temperatures, and precipitation. J Clim 13(24):4358-4365

Wang B (2006) The Asian Monsoon. Springer, Berlin/Heidelberg, p 799

Wang HJ, Chen HP (2016) Understanding the recent trend of haze pollution in eastern China: roles of climate change. Atmos Chem Phys 16(6):1-18

Wang L, Feng J (2011) Two major modes of the wintertime precipitation over China (in Chinese). Chin J Atmos Sci 35(6):1105-1116

Wang B, Wu R, Fu X (2000) Pacific-East Asian teleconnection: how does ENSO affect East Asian climate? J Clim 13(9):1517-1536

Wang B, Wu R, Li T (2003) Atmosphere-warm ocean interaction and its impacts on Asian-Australian monsoon variation. J Clim 16(8): $1195-1211$

Wang HJ, Chen HP, Liu JP (2015) Arctic sea ice decline intensified haze pollution in eastern China. Atmos Oceanic Sci Lett 8(1):1-9

Wang X, Zhong S, Bian X, Yu L (2019) Impact of 2015-2016 El Niño and 2017-2018 La Niña on $\mathrm{PM}_{2.5}$ concentrations across China. Atmos Environ 208:61-73
Wu D, Tie X, Li C, Ying Z, Lau KH, Huang J, Deng X, Bi X (2005) An extremely low visibility event over the Guangzhou region: a case study. Atmos Environ 39(35):6568-6577

Wu D, Wu XJ, Li F, Tan HB, Chen J, Chen HH, Chen HZ, Cao ZQ, Li HY, Sun X (2013a) Long-term variations of fog and mist in mainland China during 1951-2005. J Trop Meteorol 19(2):181-187

Wu M, Wu D, Fan Q, Wang BM, Li HW, Fan SJ (2013b) Observational studies of the meteorological characteristics associated with poor air quality over the Pearl River Delta in China. Atmos Chem Phys 13(21):10755-10766

Xiao D, Li Y, Fan S, Zhang J, Sun RH, Wang JH, Y. (2015) Plausible influence of Atlantic Ocean SST anomalies on winter haze in China. Theor Appl Climatol 122:249-257. https://doi.org/10.1007/s00704014-1297-6

Xu X, Ding G, Zhou Li, Zheng X, Bian L, Qiu J, Yang L, Mao J (2003) Localized 3D-structural features of dynamic-chemical processes of urban air pollution in Beijing winter. Chinese Sci Bull 48(8):819 825

Xu X, Zhao T, Liu F, Gong SL, Kristovich D, Lu C, Guo Y, Cheng X, Wang Y, Ding G (2016) Climate modulation of the Tibetan Plateau on haze in China. Atmos Chem Phys 16:1365-1375. https://doi.org/ 10.5194/acp-16-1365-2016

Yan L, Liu X, Yang P, Yin ZY, North GR (2011) Study of the impact of summer monsoon circulation on spatial distribution of aerosols in East Asia based on numerical simulations. J Appl Meteorol Climatol 50(11):2270-2282

Yin Z, Wang H (2017) Role of atmospheric circulations in haze pollution in December 2016. Atmos Chem Phys 17(18):11673-11681

Yin Z, Wang H (2018) The strengthening relationship between Eurasian snow cover and December haze days in central North China after the mid-1990s. Atmos Chem Phys 18(7):4753-4763

Yu X, Wang Z, Zhang H, Zhao S (2019) Impacts of different types and intensities of El Niño events on winter aerosols over China. Sci Total Environ 655:766-780

Zhang RH, Sumi A (2002) Moisture circulation over East Asia during El Niño episode in Northern winter, spring and autumn. J Meteorol Soc Jpn 80:213-227

Zhang RH, Sumi A, Kimoto M (1996) Impact of El Niño on the East Asian monsoon: a diagnostic study of the ' $86 / 87$ and ' $91 / 92$ events. J Meteorol Soc Jpn 74(1):49-62

Zhang R, Sumi A, Kimoto M (1999) A diagnostic study of the impact of El Niño on the precipitation in China. Adv Atmos Sci 16(2):229 241

Zhang L, Liao H, Li J (2010) Impacts of Asian summer monsoon on seasonal and interannual variations of aerosols over eastern China. J Geophys Res Atmos 115(D7):2232-2232

Zhang XY, Wang YQ, Niu T, Zhang XC, Gong SL, Zhang YM, Sun JY (2012) Atmospheric aerosol compositions in China: spatial/ temporal variability, chemical signature, regional haze distribution and comparisons with global aerosols. Atmos Chem Phys 12:779 799. https://doi.org/10.5194/acp-12-779-2012

Zhang RH, Li Q, Zhang RN (2014) Meteorological conditions for the persistent severe fog and haze event over eastern China in January 2013. Sci China Earth Sci 57:26-35. https://doi.org/10.1007/ s11430-013-4774-3

Zhao TL, Gong SL, Huang P, Lavoué D (2012) Hemispheric transport and influence of meteorology on global aerosol climatology. Atmos Chem Phys 12(16):7609-7624

Zhao S, Li J, Sun C (2016) Decadal variability in the occurrence of wintertime haze in central eastern china tied to the pacific decadal oscillation. Sci Rep 6:27424. https://doi.org/10.1038/srep27424 
Zhao S, Zhang H, Xie B (2018) The effects of El Niño-Southern Oscillation on the winter haze pollution of China. Atmos Chem Phys 18(3):1863-1877

Zhong Q, Huang Y, Shen H, Chen Y, Chen H, Huang T, Zeng E, Tao S (2017) Global estimates of carbon monoxide emissions from 1960 to 2013. Environ Sci Pollut Res 24:864-873

Zhou LT, Wu R (2010) Respective impacts of East Asian winter monsoon and ENSO on winter rainfall in China. J Geophys Res Atmos 115:D02107. https://doi.org/10.1029/2009JD012502
Zhu J, Liao H, Li J (2012) Increases in aerosol concentrations over eastern China due to the decadal-scale weakening of the East Asian summer monsoon. Geophys Res Lett 39(9):L09809-L09814

Publisher's note Springer Nature remains neutral with regard to jurisdictional claims in published maps and institutional affiliations. 